\title{
Sustainable Agricultural Systems: A Bibliometrics Analysis of Ecological Modernization Approach
}

\author{
Lucia Rocchi *(D), Antonio Boggia and Luisa Paolotti \\ Department of Agricultural, Food and Environmental Science, University of Perugia, Borgo XX Giugno, 74, \\ 06121 Perugia, Italy; antonio.boggia@unipg.it (A.B.); luisa.paolotti@gmail.com (L.P.) \\ * Correspondence: lucia.rocchi@unipg.it
}

Received: 28 October 2020; Accepted: 14 November 2020; Published: 18 November 2020

\begin{abstract}
Agricultural systems need to be more sustainable. Nowadays, the global food production has a remarkable impact in terms of greenhouse gases production, terrestrial acidification, eutrophication and land consumption. Moreover, one of the effects of unsustainable agriculture is depletion of ecosystem services (ES) on which agricultural systems themselves are dependent. Alternative agricultural systems are possible: the aim of this review was to analyze one of these alternative systems, i.e., strong ecological modernization, to understand relevant topics and current state of the art connected with it. As a result that strong ecological modernization can be considered an ecosystem services-based farming system, we focused on the development of topics related to ecosystem services but also to diversification. The review has been conducted applying a bibliometrics approach to recognize the main papers, authors, organization and countries, as well as trend topics and main themes investigated. The results showed that basic research content involves agrobiodiversity, agroecology and diversified farming systems. At the same time, the review revealed a lack about the social and economic dimensions of sustainability that need to be addressed for promoting a true transition to a strong ecological modernization.
\end{abstract}

Keywords: ecological modernization; bibliometrics; ecosystem services; agrobiodiversity; agroecology

\section{Introduction}

Modern agriculture is characterized by an intensification of large-scale activities to achieve higher output levels. This approach has been particularly evident during the last 50 years, due to a growing earth population which needed to be fed [1]. The results of such an intensification are several and serious negative environmental externalities [2]. Nowadays, the global food production has a remarkable impact in terms of greenhouse gases production, terrestrial acidification, eutrophication and land consumption, in particular if considering animal sectors [3-8]. Therefore, one of the primary challenges of modern agriculture is to reduce external inputs and environmental impacts, while still being productive enough. Moreover, one of the effects of intensification of agriculture is depletion of ecosystem services (ES) [9], which can be a huge problem for agricultural production. There is clear recognition that agricultural systems are dependent on ES for producing goods and at the same time a source themselves of important ES, including a wide range of joint non-marketed ones [10]. The flows of ecosystem services depend directly on how agricultural ecosystems are managed and upon the diversity, composition and functioning of remaining natural ecosystems in the landscape [11]. Finding a balance between production and consumption of ES is the way to reach a long-term sustainability for agriculture.

Ecological modernization of agriculture has been promoted as a possible solution since the 1990s [12]. There are two forms of ecological modernization of agriculture: weak and strong [13,14]. Weak ecological modernization aims to improve input use efficiency, mainly using new technologies, with the scope to minimize the environmental impacts of farming systems. Weak modernization does 
not criticize the specialization or intensification of agricultural. According to Duru et al. [15] it is the dominant pathway between the two. Strong ecological modernization supports the increase of agrobiodiversity and adds the importance of diversification to some principles of the weak approach (e.g., waste recycling or input-use optimization/reduction) [14,15]. Diversification allows developing ecosystem services, favoring above all non-market ones at field, farm and landscape levels $[14,15]$. Strong ecological modernization currently exists only as a niche and there is not a clear definition for it, neither a clear distinction from the weak one [15].

The aim of this paper was to analyze the subject of strong ecological modernization, in order to understand relevant topics and current state of the art connected with it. In particular, we would like to investigate how research has developed until now the different themes related to strong ecological modernization, which are the most investigated topics and which the most active research fields. In addition, we focused on the aspect of diversification, within strong ecological modernization, for investigating how important diversification is for boosting the ecosystem services in agriculture.

In order to reach these aims, we conducted a comprehensive literature review on the trends and applications of strong ecological modernization. In particular, we focused on the development of topics related to diversification and ecosystem services, such as intercropping, multicropping and agroforestry. The review has been conducted applying a bibliometric approach to recognize the main papers, authors, organization and countries connected with it. Then, we applied cluster analysis on a keyword network, based on the abstracts of the papers to better understand frontiers and trending topics.

The structure of this article is as follows. Section 2 introduces the data collection and research methods. Section 3 shows the research results analyzing three aspects: the research overview, the main research's basic content, then the trending topics. Section 4 summarizes the overall situation and proposes suggestions for future research.

\section{Materials and Methods}

\subsection{Data Collection}

Data collection has been based on the Web of Science (WoS) core collection platform, considering the period 1985-2020, aware that 2020 is an incomplete year. WoS can be considered the most authoritative scientific and technical literature indexing database as well as an ideal data source for bibliometric investigations [16]. As strong ecological modernization aims mainly to develop diversified farming systems, to manage and support ecosystem services in general and agrobiodiversity in particular [14], the following research string has been applied: TS $=$ ("ecosystem servic") AND TS $=($ cropdiversity $)$ OR TS $=($ agroecology $)$ OR TS $=($ diversified farming system $)$ OR TS $=$ (ecoagriculture) OR TS $=$ (multicropping) OR TS $=$ (agrobiodiversity). The keywords chosen have been selected to catch the involvement of ecosystem services in agriculture, as well as all the approach which enhance agrobiodiversity. A total of 3573 publications were found; then we excluded non-English works and selected only journal articles as they represent original scientific development, for obtaining 2407 papers which are the core of the analysis.

\subsection{Analytical Methods}

Bibliometric analysis has been carried out using CiteSpace ver. 5.7 [17,18]. CiteSpace is a free Java-based application for visualizing and analyzing citations and contents in scientific literature, which combines cluster analysis, social network analysis and many other methods. During the last years, several authors applied CiteSpace to very different fields such as rural landscape [19], climate change and tourism [20] or freshwater pollution by microplastics [21].

The 2407 selected articles were imported into CiteSpace, with each time slice set to one year. As the highest number of publications in a single year within the specified time span was 397 articles in 2019, we specified Top $N=397$ to enable full visual analysis of the data, otherwise the software selects the Top $\mathrm{N}$ of 50 for generating the network. Research frontiers and trending topics with strong 
timeliness were searched across the whole analysis period (1985-2020), and the remaining factors were set by default in the software.

The main feature of CiteSpace is the network analysis, presented in the form of nodes $(\mathrm{N})$ and lines (E). The size of nodes reflects the frequency of relevant data references or occurrences, while the lines indicate the relationship between the nodes, and the thickness of the lines reflects the strength of links between data [19]. The analysis can be performed in several ways, allowing also to choose a single node type or multiple concurrent node types. The default node type is Cited References, which allows the creation of the Co-cited references and the networks are made of co-cited references. Other interesting networks are the Collaborative (node type Author), Co-citation (node type Reference), Co-occurrence (node type Category).

The analysis of the core has been performed following the protocol developed by Wu et al. [19]. Firstly, we performed a network analysis, which allows to explore the knowledge domain (i.e., numbers of publications, countries distribution, cooperation network). For some domains (i.e., countries) betweenness centrality analysis has been performed. The term 'betweenness' derived by the fact that it measures the connection of an arbitrary pair of nodes in the network in which the node is part of the connecting path [18]. A high value of betweenness centrality means that the node connects two or more large groups of nodes with the node itself in-between. For instance, if a country has a high value of betweenness centrality, probability it collaborates with several other countries. CiteSpace highlights nodes with high betweenness centrality by means of purple trims, while the strength of betweenness centrality is the thickness: the thicker, the stronger.

Then, we performed a Co-occurrence analysis and time zone chart of keywords and a co-citation clustering analysis of the research core. The clustering effect was measured using modularity and silhouette. Modularity is a quality index and can be defined as a normalized tradeoff between edges covered by clusters and squared cluster degree sum [22]. To measure the degree of modularity, the $Q$ value can be used. If $Q \geq 0.3$ then the modularization of the network is significant. The higher the $Q$ value, the better the quality of clustering. Silhouette (S) refers to a method of interpretation and validation of consistency within clusters of data. It provides a succinct measure of the homogeneity of networks. If $S \geq 0.5$, then the result of clustering is reasonable; as $S$ moves closer to 1 , the homogeneity of the network increases. However, note that in case of a small cluster size, a high homogeneity does not have a high significance but maybe it reflects the citing behavior or preferences of one single work [18].

Finally, we performed burst detection on citation, authors and noun-term. The burst detection in CiteSpace is based on Kleinberg's algorithm and allows to capture a huge change of frequency of an entity over a specific time [23]. In CiteSpace, citation and occurrence burst are both supported. Performing the citation burst analysis is useful to find evidence of an association among a specific publication and a surge of citations. Applied to the author- type node burst-detection shows those authors who have rapidly increased the number of publications. Burst-detection of noun-term identifies the emergent terms regardless of how often their host articles are cited, for identifying the trends.

\section{Results}

\subsection{Overview of Research}

\subsubsection{Overview of Papers Published}

Over the considered period (1985-2020), the number of published research shows a growing trend, although in some years there are minor reductions (Figure 1a). Since 2013, there was a rapid rise of the published papers, proving a recent increasing interest for the topic. A particularly high growth rate is between 2012 and 2013 (+39\%), while the largest number of articles (397) was published in 2019 . Note that almost the half of the papers have been published in the last four years. The citations started to grow markedly since 1999 in a very rapid matter (Figure 1b). 


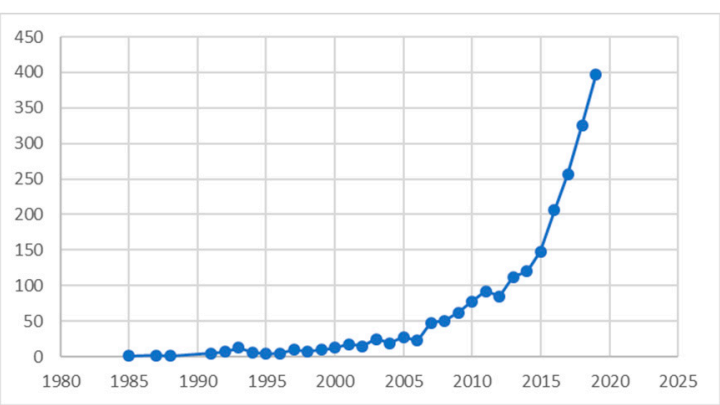

(a)

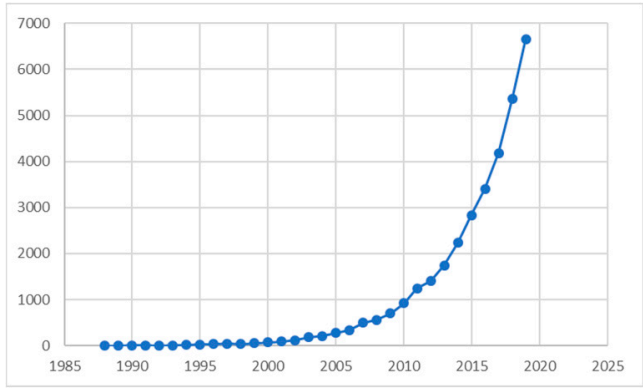

(b)

Figure 1. Overview of papers published and citations: (a) published paper; (b) Citation. In both the graphs the year 2020 is not reported, as it is an incomplete year, which generates an unrealistic trend.

\subsubsection{Authors: Core Articles and Citations}

Using authors as node type, CiteSpace produced a network about author cooperation, resulting in 418 nodes and 783 lines connecting them. Among authors, 17 published at least ten articles. Altieri and Mendez, who published the largest number of articles, had 18 articles included in the WoS database, followed by Pascual and Zimmerer with 17. The academic background of the most productive authors is mainly environmental sciences, ecology and agriculture. There are some relatively dominant academic associations (Figure 2).

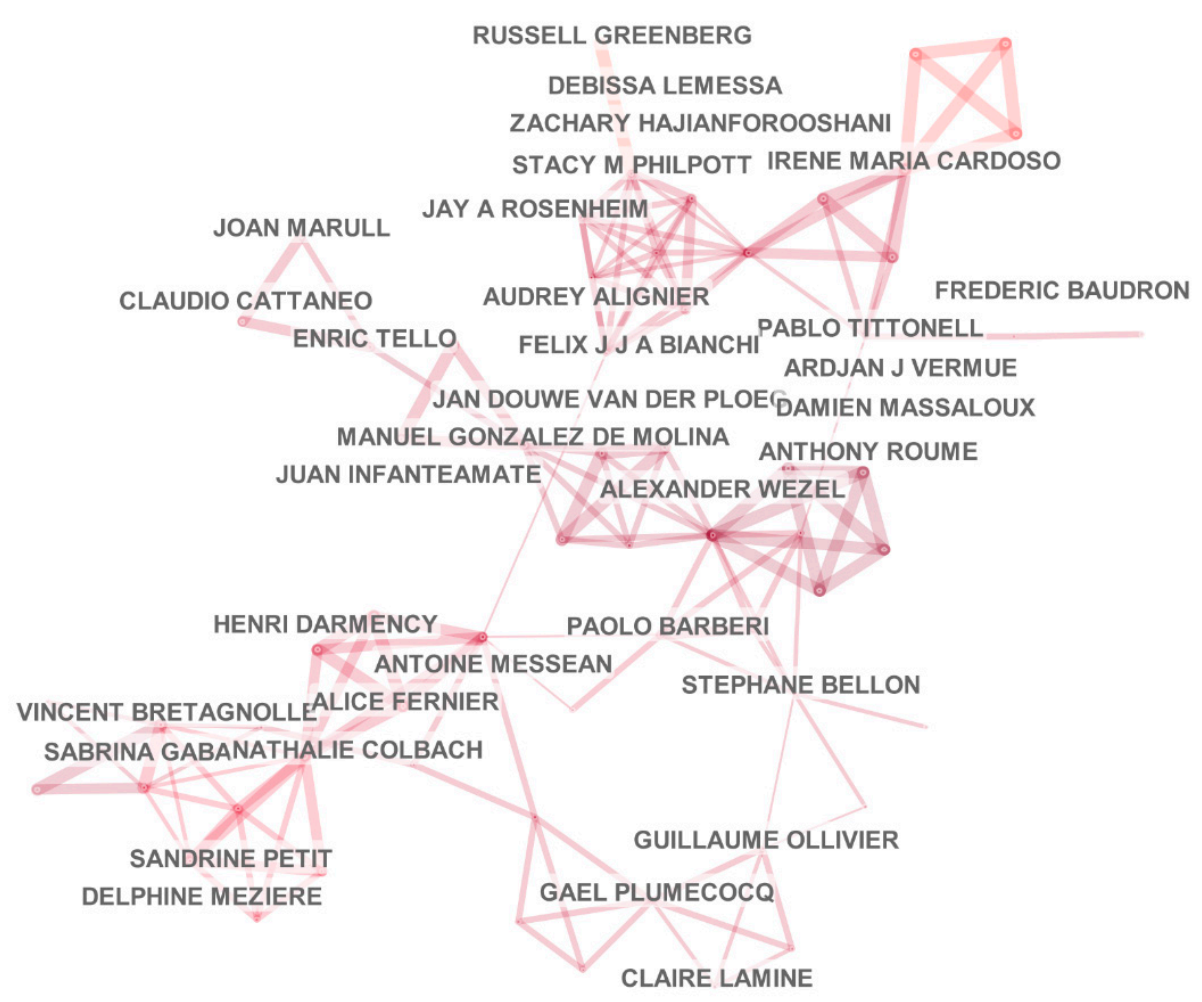

Figure 2. Authors network.

We performed a burst detection applied to the node type of author, to see those authors who have rapidly increased the number of publications (Figure 3). The majority of the authors (13 out of 16) in Figure 3 have their burst starting from 2013, which is also the year that identified a clear growth in the total number of publications. Mendez, who has the strongest burst, is also one of the two most productive authors. 


\section{Top 16 Authors with the Strongest Citation Bursts}

\begin{tabular}{lrrr}
\multicolumn{1}{c}{ Authors } & \multicolumn{1}{c}{ Year Strength Begin End } \\
V ERNESTO MENDEZ & 1985 & $\mathbf{8 . 7 7 6 9} 2010$ & 2014 \\
SANDRINE PETIT & 1985 & $\mathbf{6 . 7 6 3 7} 2014$ & 2016 \\
UNAI PASCUAL & 1985 & $\mathbf{6 . 7 3 6 3} 2010$ & 2015 \\
STEPHAN RIST & 1985 & $\mathbf{4 . 2 7 9 6} 2014$ & 2015 \\
JOHANNA JACOBI & 1985 & $\mathbf{4 . 2 7 9 6} 2014$ & 2015 \\
NATHALIE COLBACH & 1985 & $\mathbf{4 . 2 5 2 9} 2015$ & 2017 \\
KARL S ZIMMERER & 1985 & $\mathbf{4 . 0 2 3 3} 2013$ & 2016 \\
ADAM G DRUCKER & 1985 & $\mathbf{4 . 0 1 1 1} 2011$ & 2013 \\
IVETTE PERFECTO & 1985 & $\mathbf{3 . 9 5 8 6} 2013$ & 2016 \\
KATLYN S MORRIS & 1985 & $\mathbf{3 . 8 2 5 9} 2010$ & 2013 \\
CLAIRE KREMEN & 1985 & $\mathbf{3 . 6 8 7} 2012$ & 2015 \\
VICTORIA REYESGARCIA & 1985 & $\mathbf{3 . 6 4 4 2} 2012$ & 2014 \\
MIGUEL AALTIERI & 1985 & $\mathbf{3 . 1 4 6 7} 2015$ & 2017 \\
\hline ANTOINE MESSEAN & 1985 & $\mathbf{2 . 5 1 7 5} 2017$ & 2018 \\
\hline PAOLO BARBERI & 1985 & $\mathbf{2 . 5 1 7 5} 2017$ & 2018 \\
RACHEL BEZNER KERR & 1985 & $\mathbf{2 . 2 6 3 7} 2016$ & 2017 \\
\hline
\end{tabular}

Figure 3. Authors with the strongest citation bursts, sorted by burst strength.

\subsubsection{Distribution of Research Disciplines}

Using the node type Category, it is possible to build a network of the subject categories. The network produced is formed by 113 nodes and 625 lines (Figure 4). Totally, 87 categories have been identified. The category Agriculture exceeded 1000 papers; Environmental sciences and ecology exceeded 800 papers. The betweenness-centrality value obtained more than 0.1 in 39 disciplines (e.g., Agriculture, Environmental sciences and ecology, Plant science and Business and Economics). Moreover, some categories, like Biotechnology and Applied microbiology, Energy and Fuel, Business and Economics and Plant Sciences, have a relatively high betweenness-centrality value but few publications: probably, these disciplines play a pivotal role in the construction of the interdisciplinary collaboration and research system.

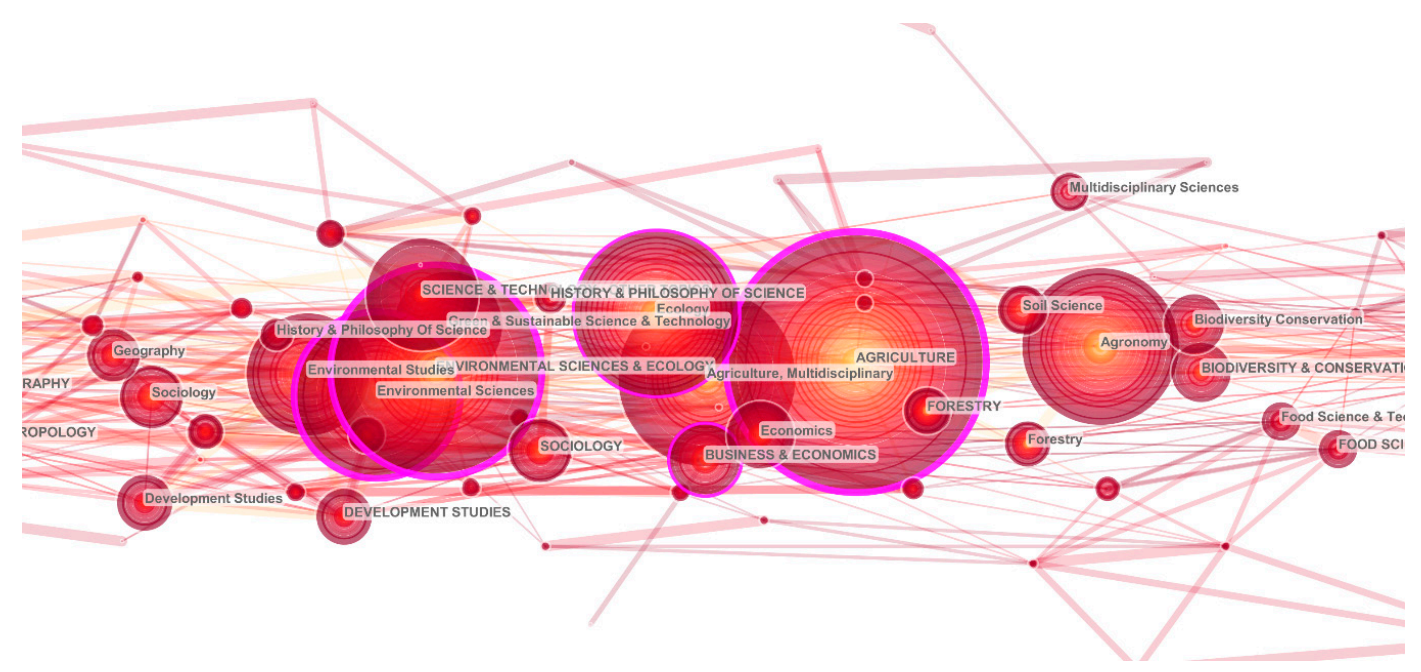

Figure 4. Network of the subject categories; purple trims highlight betweeness centrality.

\subsubsection{Countries and Organization}

The cooperation network of countries showed 86 nodes and 854 lines connecting the nodes (Figure 5). The most productive country is USA (703 papers), the second country, France, has half of the papers of USA (342). England, Italy and Brazil are also very productive. 


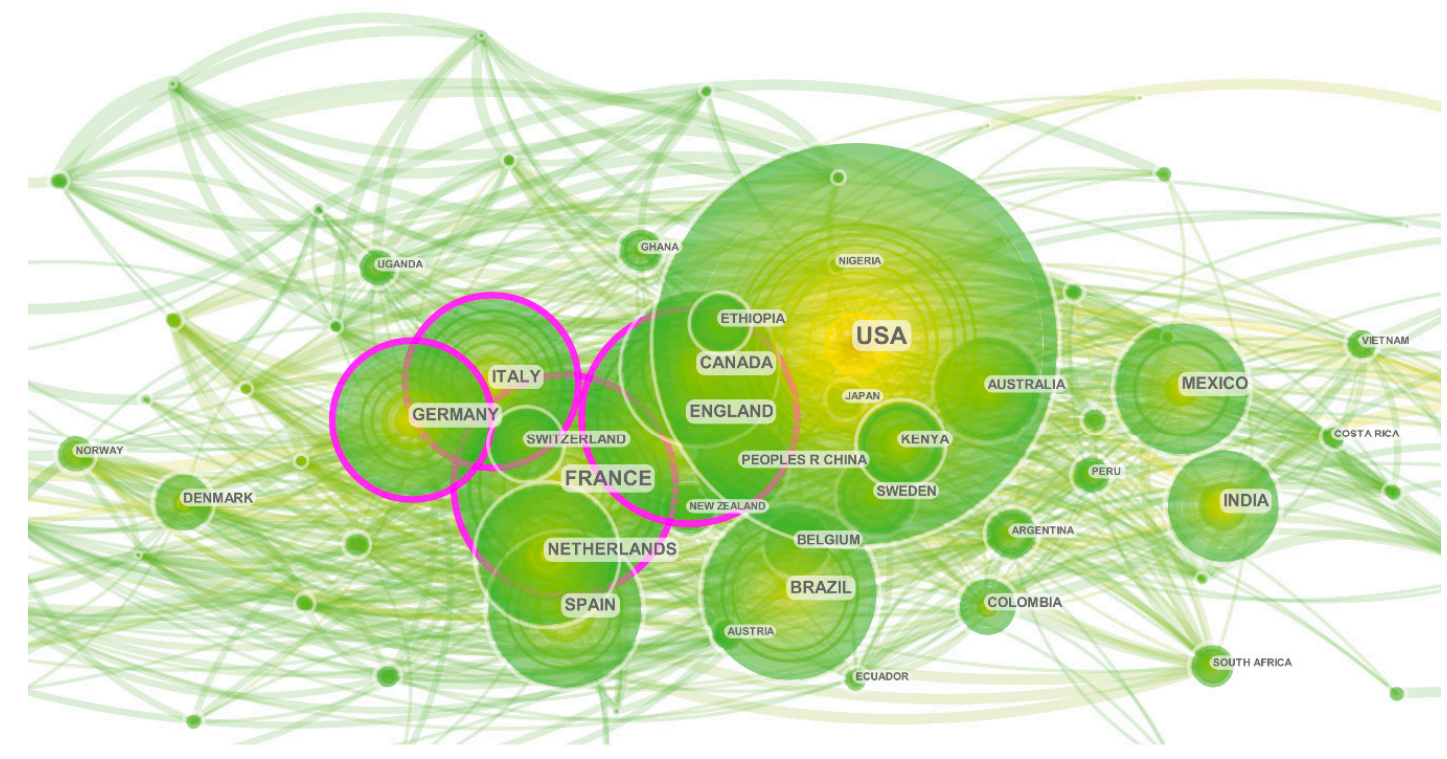

Figure 5. Countries cooperation network.

Germany, France, Italy and England have the highest betweenness centrality, as it is highlighted by the thick purple lines around the node. In addition, Ethiopia and Argentina are among the 10 nodes with the highest betweenness centrality, although they have a relative low number of papers in comparison to the countries of the same group. Note that 5 of the best 10 countries for betweenness centrality are part of the European Union. The common institutional and research framework provided by the European Union may produce a strong research collaboration across its countries, which emerges through betweenness centrality. This aspect seems to be supported also by the organizations network $(\mathrm{N}=404 ; \mathrm{E}=1322)$, in which the European institutions and universities have the higher level of betweenness (Figure 6). INRA (Institut national de la recherche agronomique- National Institute of agronomic research) plays a crucial role both in terms of number of papers (almost $40 \%$ of the France publications) and of betweenness centrality. Therefore, INRA plays a pivot role among different other research institutes, probably European. On the contrary, the USA contribution in terms of papers is scattered across several institutions. The three most productive universities are University of California, Berkeley, Cornell University and University of California, Davis. The sum of their works is around $20 \%$ of all USA papers.

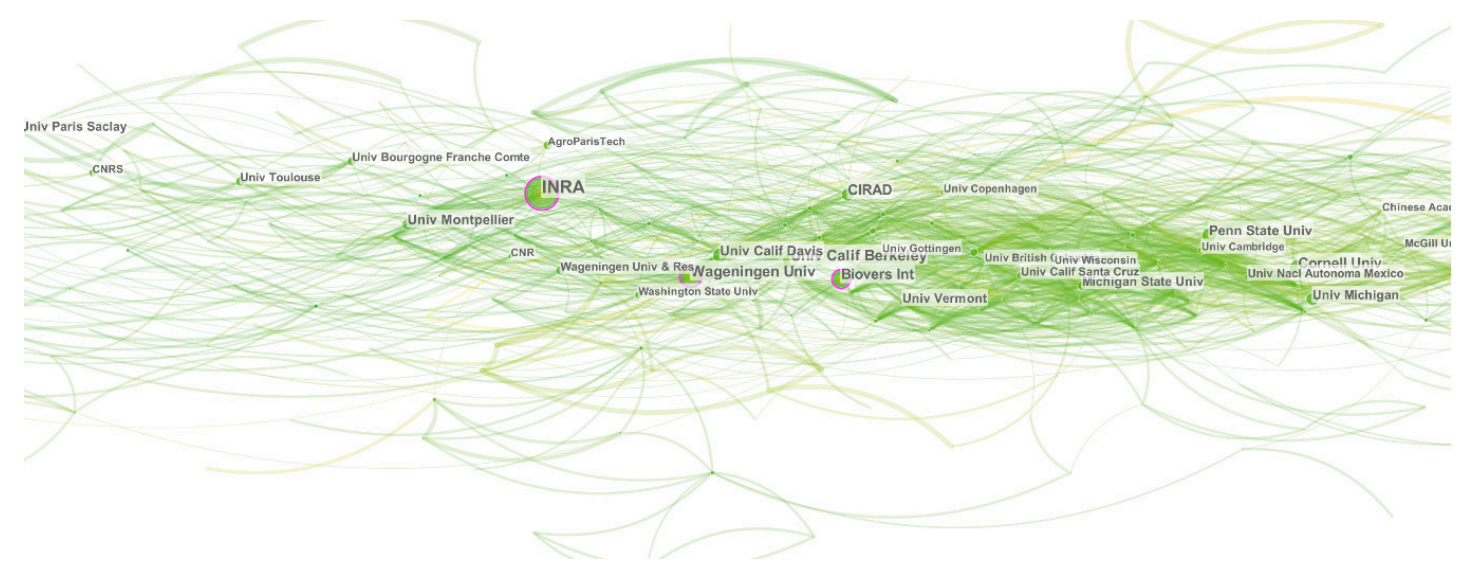

Figure 6. Main organizations. 


\subsection{Main Themes}

\subsubsection{Keywords Analysis}

For better understanding the main themes faced in the ecological modernization approach, we performed a keywords co-occurrence analysis and a burst detection applied to the keywords. After the elimination of the retrieval terms, the five most used keywords are 'agroecology' (934), 'agrobiodiversity' (384), 'biodiversity' (369), 'agriculture' (362) and 'management' (344). Considering also when they first appeared in the literature corpus (Figure 7), 'agrobiodiversity' and 'biodiversity' are more recent then other keywords, including 'diversity' and 'management'. Due to visualization reasons, Figure 7 is based on the keywords' frequency of the top ten papers for each year.

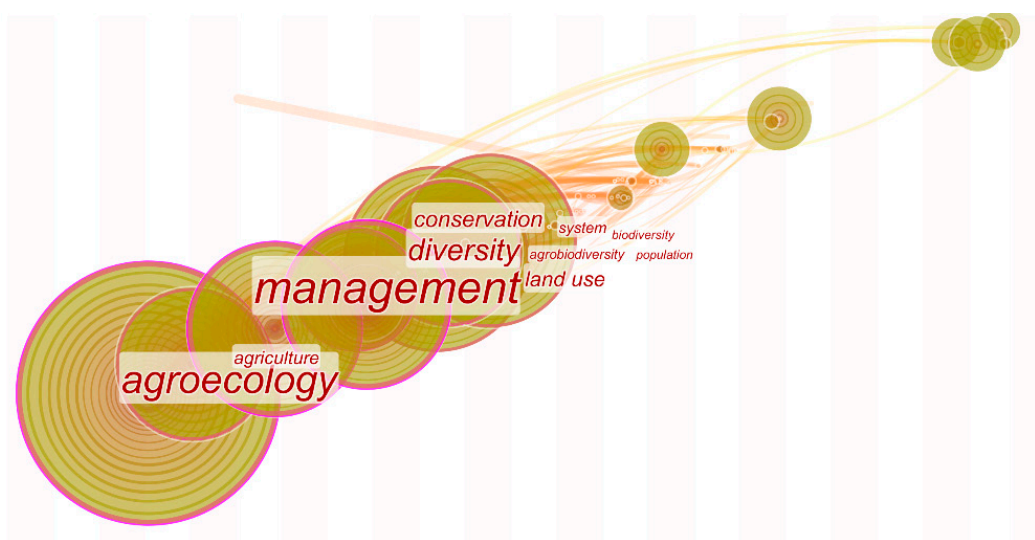

Figure 7. Keyword time zone map.

All the keywords have a low or very low level of between centrality; however, the keyword holding the highest between centrality level is 'agricultural landscape'. This result can be interpreted in two ways. The first is considering the definition of agricultural landscape itself. Since the agriculture landscape is the result of interactions between farming activities and the natural assets in a certain area, it plays a central role among several topics linked to ecological modernization. Instead, using the Tscharntke et al. [24] interpretation, we can affirm that the landscape perspective is the only possible way to relate agrobiodiversity and ecosystem services management to the management of the land use and to agriculture.

Detection of the burst applied to keywords shows the fast growing of topics over time: burst keywords refers to keywords heavily cited by articles over a period. Figure 8 reports such bursts ranked by the beginning of the burst. 'agroecology', which is also the keyword with the strongest burst, appeared in 1992, followed by 'sustainable agriculture' the next year. Although the second is weaker in terms of burst, it is more persistent and it last for almost two decades. On the contrary, 'organic farming' presents the shortest burst. The second and third keywords according to the strength of the burst are 'agrobiodiversity' and 'diversity', proving that diversification is a main topic in strong ecological modernization. None of the keywords identified persists till nowadays. 


\section{Top 25 Keywords with the Strongest Citation Bursts}

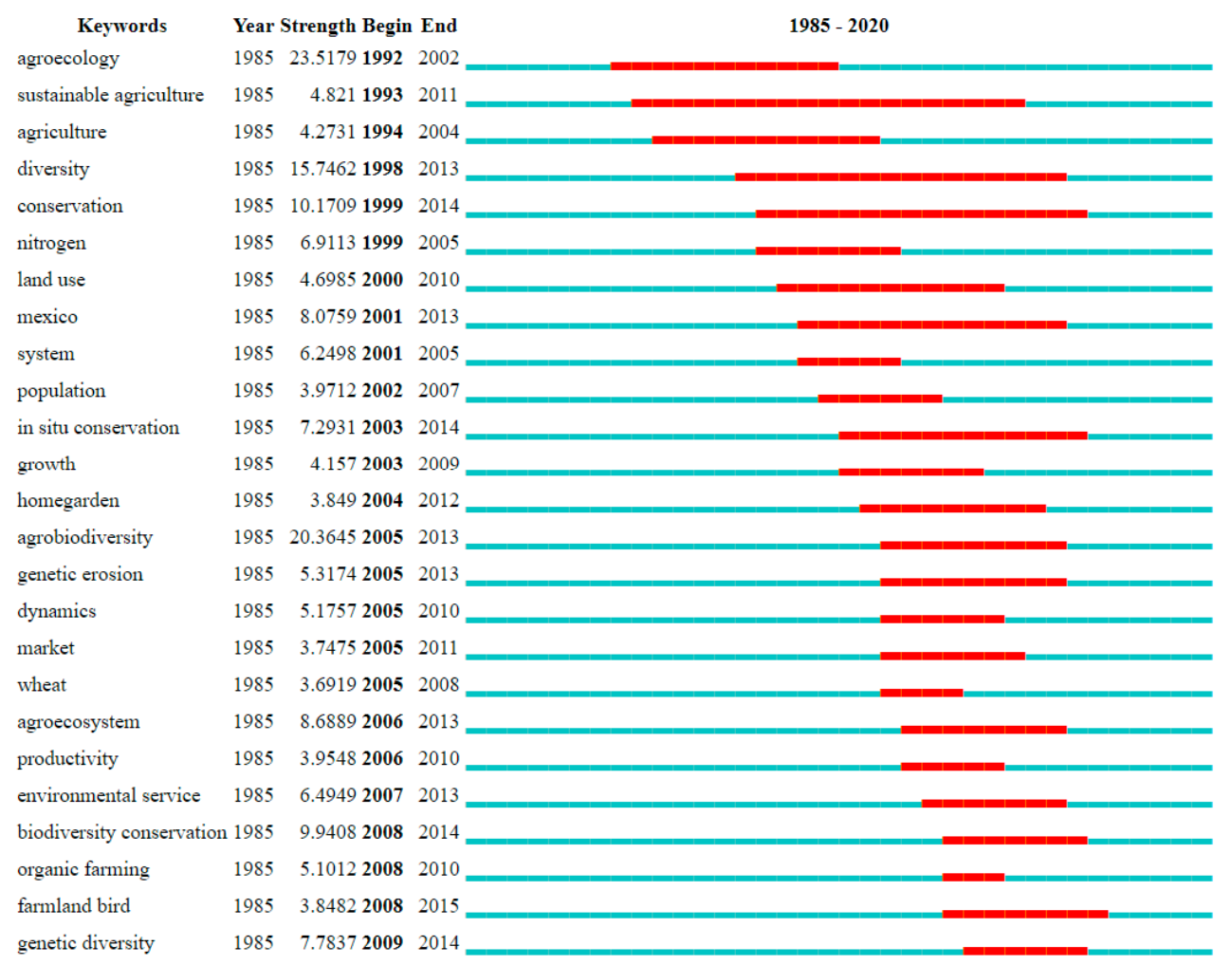

Figure 8. Keyword citation burst.

\subsubsection{Clusters Analysis}

In order to deepen the analysis of the themes, a co-citation cluster analysis has been performed using as nodes the cited references. The network produced is built up by 1390 nodes and 6137 lines. The cluster analysis has been processed using log-likelihood ratios (LLR) algorithm among the ones available in CiteSpace as it usually gives the best result in terms of uniqueness and coverage [18], and labels given according to the abstract. The quality of the clustering is given by $Q=0.7212$ and an average silhouette equal to $S=0.3423$. These values mean that the network is reasonably divided into loosely couple clusters but the homogeneity of them on average is not very high. Figure 9 reports the results of the clustering. Clusters are numbered starting from cluster \#0, which is the one with the largest number of references. Each cluster can be considered as a theme, a topic or a line of research. Then we selected five clusters, according to the dimension and silhouette values, for going in deep in the analysis (Table 1). The most cited papers have been read and, using also the trends highlighted by the keyword's analysis, we identified five lines of research, which can be considered as predominant. 


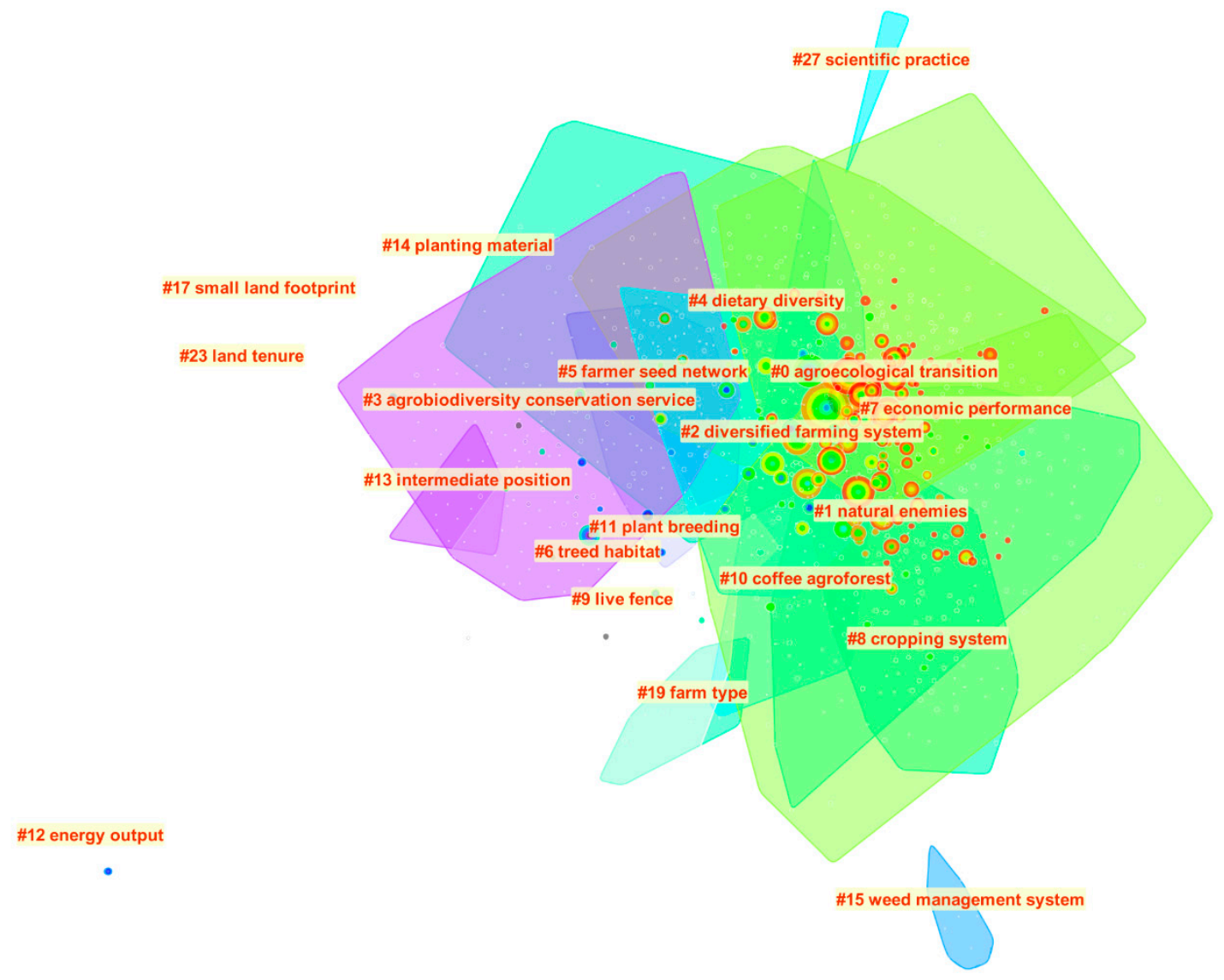

Figure 9. Clustering of co-citation references.

Table 1. High-frequency co-words of co-citation clustering (top 5).

\begin{tabular}{|c|c|c|c|c|}
\hline Cluster ID & Size & Silhouette & Mean (year) & Core Noun Terms \\
\hline$\# 0$ & 200 & 0.683 & 2013 & $\begin{array}{l}\text { agroecology transition; food sovereignty; } \\
\text { agroecological practice; agroecological paradigm; } \\
\text { Latin America; sustainability transition }\end{array}$ \\
\hline$\# 1$ & 157 & 0.729 & 2013 & $\begin{array}{l}\text { natural vegetation; biological control; organic } \\
\text { farming; agricultural intensification; habitat amount } \\
\text { carbon sequestration; soil quality; conventional }\end{array}$ \\
\hline \#2 & 117 & 0.745 & 2008 & $\begin{array}{c}\text { farming system; diversified farming practice; } \\
\text { water-holding capacity }\end{array}$ \\
\hline \#3 & 108 & 0.823 & 2006 & $\begin{array}{l}\text { cultural landscape; conservation area; on-farm } \\
\text { conservation; conservation service; policy option }\end{array}$ \\
\hline$\# 4$ & 104 & 0.752 & 2013 & $\begin{array}{l}\text { crop diversity; food group; semi-arid area; land use; } \\
\text { livestock diversity }\end{array}$ \\
\hline
\end{tabular}

\#0 Cluster Agroecology

Initially started as grassroots movements, nowadays agroecology is recognized as a promised alternative to intensified agricultural approach [25]. Moreover, it can be seen as a way for the transition toward a more sustainable food system, in which innovation crosses the farm borders, settings as combinations of farming practices, agriculture type and value chain [26]. Altieri and Toledo described the agroecology transition as a threefold 'agroecological revolution', applied in an epistemological, technical and social direction [27]. The core of such revolution leans on the regeneration and conservation of agrobiodiversity as well as on input reduction. In addition, the role of the peasants and local movements is crucial for success $[27,28]$. The agronomic interpretation of agroecology only as a practice may lead to a misinterpretation of the social dimensions of agroecology, 
which allows to criticize those food systems approaches that undervalue the farmers' contribution in determining their social context $[29,30]$. Moreover, some crucial drivers which allow the agroecology transition include the recognition of a crisis that motivates the search for alternatives, the presence of social organization, and favorable market and policies in the direction of the food sovereignty [31].

However, although agroecological transition is occurring, with Latin America leading [27], there is a problem of agroecology's diffusion and in the recent literature there is a deep analysis of the barriers to agroecology and sustainability transition, as well about the limits to the diversification approach [26]. Using Technological Innovation Systems approach in a Nicaraguan case study, Schiller et al. [32] found that among the main barriers to agroecological transition there are weak guidance, insufficient capacities and quantities of resources, and the lack of market development. Moreover, if the transition does not use a participatory approach, there is the risk that these will be conventionalized and co-opted, especially in larger territories [33]. The participatory approach, also, has a key importance in the transition, as agroecology is part of the "science with people" philosophy, and there is the need of collaborative strategies between scientists and farmers for co-creating and exchanging knowledge [31,34,35].

\section{\#1 Enhance Ecosystem Services and Agrobiodiversity}

Strong ecological modernization is based on agrobiodiversity and the ecosystem services provided. Both the local farm management and the surrounding landscape potentially affect the provision of ecosystem services, as pollination [36-38]. Pest and weed control and pollination can be augmented by diversified practices, although evidence suggests that these practices may often be insufficient. Lichtenberg et al. [39] found that both organic farming and in-field plant diversification carry out the strongest effects on pollinators and predators, suggesting how these management schemes can facilitate ecosystem service providers without augmenting pest populations. However, to conserve high-quality habitats and services, also large spatial area plans are needed, integrating multiple conservation approaches at landscape scale [37]. Although some works are presented (as [40]), few papers are still present about the full range of benefits and costs of a productive diversified agroecosystem in which several species, vegetables and crops, interact.

\section{\#2 Diversified Farm Systems}

Diversified Farming Systems (DFS) can be defined as all the practices at farm and landscape levels that intentionally include functional biodiversity at multiple spatial and/or temporal scales, with the aim to maintain ecosystem services [41]. In this definition, livestock integration, non-crop planting, polycultures are all included. In DFS, there is a reciprocity between agriculture models promoted by the provision of ecosystem services and biodiversity promotion through a diversification approach [41]. Kremen and Miles [42] proved that diversified farming systems sustained agrobiodiversity and other ecosystem services, as soil quality, carbon sequestration and water-holding capacity in comparison to the conventional farms. Moreover, DFS can provide greater food security, as it contributes to the self-consumption, improved income of farmers and reduce vulnerability against climate change and variability in comparison to conventional system, even in case of livestock productions $[41,43,44]$. This is thanks to the fact that DFS gives more possibility to the farmers of adopting different strategies because of the strict connection with both traditional and contemporary knowledge, cultures, practices $[41,45]$. However, the social dimension of diversified systems has been less studied than the economic and ecological ones [46,47].

In comparison to other systems, in particular to conventional, the improvement of diversified farm system received less funding, although these produced fewer environmental and social harms [42]. DFS is not only significantly less promoted than other systems [47] but its promotion is not always effective because of a lack of connection with the environmental and agroecological concerns embodied within the DFS concept itself [42]. DFS needs an institutional environment that specifically promotes diversified agricultural practices with a broad approach [45,46]. van Zonneveld et al. [48] identified a 
weak point in the lack of support and decision making on how to diversify farm system to fit in the agroecological paradigm, particularly in case of smallholders, as well as the delay in policy action [45].

\section{\#3 Agrobiodiversity Conservations}

The erosion of agrobiodiversity can be defined as the replacement of the diverse existing pool of local plant and animal genetic resources with a smaller range of them, despite their crucial role in contributing to sustainability of agriculture systems [49]. Around the world, peasants cultivate crop genetic diversity, enabling crops adaptation to changing environmental condition [50,51]. In situ conservation of biodiversity by smallholder is proved to be a successful strategy $[50,52,53]$. Such process is undermined by the market expansion and homogenization of the field [50].

To support and enlarge in situ conservation, payment schemes, as payments for agrobiodiversity conservation services, can be useful, although some challenge for the success, as the institutional framework, are present and market niche should be developed [49,54]. Moreover, a huge attention to the conservation goals should be paid because trade-off between them may happen [55]. Some social aspects, such as inclusion, participation and planning, are crucial for agrobiodiversity management [56], as well as migration activities $[50,56]$. In addition, the governance framework must have an active and positive role in conservation, in order to encourage farmers about exchange and conservation of genetic resources [57].

\section{\#4 Dietary Diversity}

Crop diversification and livestock integration mean also dietary diversity in several situations for smallholder farm households in developing countries, although empirical evidence of such a link is still rare [58]. Some authors highlight the contribution of wild edible species from arid and semi- arid areas, in particular, for a healthy diet [59,60]; although, these results are still under investigation [61].

Motivations to crop diversity can largely vary, however, there is a centrality of consumption-related traits in semi-subsistence farmers [62]. Market transactions tend to reduce the role of farm diversity for household nutrition, while having positive effects on dietary diversity [58,62].

\subsection{Trending Topics in the Past and Current Literature}

In order to map the trending topic in the corpus, an analysis of the high-frequency words and their bursts has been performed. Figure 10 reports 20 groups of terms with the highest frequency, ranked according to the year in which the burst started.

Top 20 Terms with the Strongest Citation Bursts

\begin{tabular}{llrl}
\multicolumn{1}{c}{ Terms } & Year Strength Begin End \\
sustainable agriculture & 1985 & $7.2018 \mathbf{1 9 9 3}$ & 2009 \\
farming system & 1985 & $15.3886 \mathbf{1 9 9 7}$ & 2008 \\
sustainable development & 1985 & $4.2493 \mathbf{1 9 9 7}$ & 2010 \\
genetic resources & 1985 & $7.7746 \mathbf{1 9 9 9}$ & 2013 \\
agricultural production & 1985 & 3.73482000 & 2015 \\
cropping system & 1985 & $9.7428 \mathbf{2 0 0 0}$ & 2012 \\
agricultural biodiversity & 1985 & 10.36732000 & 2013 \\
significant difference & 1985 & $6.8374 \mathbf{2 0 0 1}$ & 2012 \\
organic marter & 1985 & $5.6005 \mathbf{2 0 0 2}$ & 2014 \\
situ conservation & 1985 & $9.3132 \mathbf{2 0 0 3}$ & 2014 \\
agrobiodiversity conservation & 1985 & 9.75022003 & 2013 \\
organic farms & 1985 & 3.7172003 & 2015 \\
winter wheat & 1985 & $5.6875 \mathbf{2 0 0 4}$ & 2009 \\
home gardens & 1985 & $5.2968 \mathbf{2 0 0 4}$ & 2013 \\
genetic erosion & 1985 & $4.0298 \mathbf{2 0 0 5}$ & 2012 \\
genetic diversity & 1985 & $10.1693 \mathbf{2 0 0 6}$ & 2013 \\
crop diversity & 1985 & $4.7654 \mathbf{2 0 0 6}$ & 2011 \\
species richness & 1985 & 6.38042007 & 2010 \\
farm households & 1985 & 4.35842007 & 2010 \\
crop yields & 1985 & 3.81262008 & 2013 \\
\hline
\end{tabular}

Figure 10. High-frequency terms and their burst time. 
Most of the bursts detected appear after 2000. Before that date, the trending topics have been related in particular to 'sustainable agriculture', which stands for 16 years, and 'farming system' in general, which shows the strongest burst. Clearly, the majority of the terms are somehow linked to agrobiodiversity and its conservation: 7 out of 20 terms. Landscape related terms do not appear among the trend topics, although in the analysis we identified a clear pivotal role for it. Moreover, diversification of crop systems seems to be marginal in comparison to other topics.

\section{Discussion}

The research questions of this study were: (1) What is the state-of-the-art connected with strong ecological modernization? (2) What are the relevant topics and research fields connected with strong ecological modernization? (3) Which of them are the most investigated so far?

As for the first question, the analysis showed that, even if strong ecological modernization is considered a niche sector, this may be true with regard to field practice, which is not yet widespread. With reference to research, we found that things are changing, with ever greater acceleration. Studies, experiments, research projects dedicated to the theme of strong ecological modernization have shown a remarkable, fast and constant growth over time. Research interest in this topic is high, well spread across countries and sectors and improving their quantitative presence. Both agriculture and environmental sciences devoted attention to those themes and the presence of long and overlapping bursts can be read as prove of a constant, not occasional or discontinuous interest of the scientific communities.

To find the relevant topics and research fields connected with strong ecological modernization, we used cluster analysis. As a result, we identified some topics and areas of research, developed in the considered period. All the five clusters identified are linked to the diversification issue. Each cluster identified a different connotation of diversification, although all connected. In particular, for agroecology approach diversity means not only enhance biodiversity through the promotion of polycultures and/or agroforestry patterns, but also diversity of approach, strategy and techniques [63]. Multiple land use strategy in agroecology is a key point, as it is the only way to ensure the resilience of the agroecosystem $[63,64]$. As a matter of fact, the integration between natural systems and agroecosystems is a key element for the resilience of the territories, for the realization of effective models of strong ecological modernization, to continuously feed the capacity of agricultural systems to provide their wide range of ecosystem services, from the provisioning, to the regulating, to the supporting, up to the cultural ones. At same time, biodiversity conservation does not mean only conservation of local varieties and species but also biological pest control and soil quality, thanks to the biotic activities [63]. In addition, the diversification present in the Diversified Farming Systems includes the management of agrobiodiversity at multiple spatial and/or temporal scales, also explicitly using agroecological knowledge and approach [41]. However, in DFS, the focus is more on the role of the farmer in defining practices from the field level to the landscape one [41].

Agroecology is the theme with the greatest research activity, followed by the enhancement of ecosystem services and agrobiodiversity. Agrobiodiversity is the diversification link across the different studies. Burst analysis of both keywords and terms highlight the overabundant presence of terms related to agrobiodiversity (i.e., genetic conservation/erosion/diversification; in situ conservation, agrobiodiversity, biodiversity conservation, etc.). This is not surprising as its capacity to generate critical ecosystem services to agriculture is proven [65].

The two themes of agroecology and enhancement of ecosystem services and agrobiodiversity are strongly linked to each other. In fact, agroecology is the key for the conservation of agrobiodiversity and, as a consequence, for the maintenance and strengthening of ecosystem services. The reference to an agroecology well placed in the context of sustainability, therefore not linked only to agronomic aspects, is evident [66]. The economic and above all social implications of agroecology, and the needs for political and regulatory guidelines are clearly discussed. The agroecological paradigm is well designed, and it can be synthesized as follows: 
- First the system and then the techniques;

- $\quad$ strong reduction of external inputs;

- $\quad$ prevention (e.g., soil health, crop adversity);

- diversification and agroecosystem services;

- transdisciplinary and participatory innovation.

As a result, from the studies it emerges clearly that the agroecological approach, based on conscious use of agrobiodiversity, is the best strategy for a long-term sustainability of agri-food systems [67].

\section{Conclusions}

Sustainable agriculture is a key argument in the current literature. However, the perfect solution to achieve it has been not yet found. Among the different approaches, strong ecological modernization seems to be one of the most promising. In comparison to other approaches, as the weak ecological modernization, its framework seems quite scattered, including approaches and themes very different.

In this framework, agroecology seems playing a great role, probably linked also to its capacity to include not only ecological and agronomic aspects but also social and economic issues. The lack of a proper governance level or of decision support for decision makers emerges in a very clear way from literature; in particular, in relation to funding and supporting framework.

The use of CiteSpace helped us in identifying in a very objective way a picture of strong ecological modernization, without artificial screening. Bibliometric analysis revealed some interesting information, as the presence of a clear network of countries and organization working on those topics in EU. Cluster analysis highlighted the presence of some clear pathways for research. Keyword analysis and noun-term detection stressed the effort of the literature core for sustainable agriculture. However, the analysis showed that although the ecological and environmental dimensions are well developed in the literature, to the connection with to the topics of ecosystem services and agrobiodiversity, social and economic research are still needed. As it emerged that strong ecological modernization is also linked to themes such as food sovereignty and diet diversity, a deeper reflection on the social and economics pillars is required for the progress of the approach itself. Moreover, this supplementary and further analysis is required not only in developing countries but also in developed countries where other types of farming approaches receive more support although they ensure a lower level of resilience to the whole food production system.

Author Contributions: L.R. contributed to conceptualization, methodology, software, validation, formal analysis, literature search, data curation, and writing-original draft preparation. A.B. contributed to conceptualization, supervision, and writing-review and editing. L.P. contributed literature search, writing-original draft preparation and writing-review and editing. All authors have read and agreed to the published version of the manuscript.

Funding: This research received no external funding

Conflicts of Interest: The authors declare no conflict of interest.

\section{References}

1. Gerland, P.; Raftery, A.E.; Ševčíková, H.; Li, N.; Gu, D.; Spoorenberg, T.; Alkema, L.; Fosdick, B.K.; Chunn, J.; Lalic, N.; et al. World population stabilization unlikely this century. Science 2014, 346, 234-237. [CrossRef] [PubMed]

2. Tilman, D.; Cassman, K.G.; Matson, P.A.; Naylor, R.; Polasky, S. Agricultural sustainability and intensive production practices. Nature 2002, 418, 671-677. [CrossRef] [PubMed]

3. Godfray, H.C.J.; Beddington, J.R.; Crute, I.R.; Haddad, L.; Lawrence, D.; Muir, J.F.; Pretty, J.; Robinson, S.; Thomas, S.M.; Toulmin, C. Food security: The challenge of feeding 9 billion people. Science 2010, 327, 812-818. [CrossRef] [PubMed]

4. Bajželj, B.; Richards, K.S.; Allwood, J.M.; Smith, P.; Dennis, J.S.; Curmi, E.; Gilligan, C.A. Importance of food-demand management for climate mitigation. Nat. Clim. Chang. 2014, 4, 924-929. [CrossRef] 
5. Mottet, A.; de Haan, C.; Falcucci, A.; Tempio, G.; Opio, C.; Gerber, P. Livestock: On our plates or eating at our table? A new analysis of the feed/food debate. Glob. Food Secur. 2017, 14, 1-8. [CrossRef]

6. Poore, J.; Nemecek, T. Reducing food's environmental impacts through producers and consumers. Science 2018, 360, 987-992. [CrossRef]

7. Springmann, M.; Clark, M.; Mason-D'Croz, D.; Wiebe, K.; Bodirsky, B.L.; Lassaletta, L.; de Vries, W.; Vermeulen, S.J.; Herrero, M.; Carlson, K.M.; et al. Options for keeping the food system within environmental limits. Nature 2018, 562, 519-525. [CrossRef]

8. Willett, W.; Rockström, J.; Loken, B.; Springmann, M.; Lang, T.; Vermeulen, S.; Garnett, T.; Tilman, D.; DeClerck, F.; Wood, A.; et al. Food in the Anthropocene: The EAT-Lancet Commission on healthy diets from sustainable food systems. Lancet 2019, 393, 447-492. [CrossRef]

9. Bommarco, R.; Kleijn, D.; Potts, S.G. Ecological intensification: Harnessing ecosystem services for food security. Trends Ecol. Evol. 2013, 28, 230-238. [CrossRef]

10. Palm, C.; Blanco-Canqui, H.; DeClerck, F.; Gatere, L.; Grace, P. Conservation agriculture and ecosystem services: An overview. Agric. Ecosyst. Environ. 2014, 187, 87-105. [CrossRef]

11. Zhang, H.; Gao, Y.; Hua, Y.; Zhang, Y.; Liu, K. Assessing and mapping recreationists' perceived social values for ecosystem services in the Qinling Mountains, China. Ecosyst. Serv. 2017, 3, 7. [CrossRef]

12. Mastrangelo, M.E.; Aguiar, S. Are Ecological Modernization Narratives Useful for Understanding and Steering Social-Ecological Change in the Argentine Chaco? Sustainability 2019, 11, 3593. [CrossRef]

13. Horlings, L.G.; Marsden, T.K. Towards the real green revolution? Exploring the conceptual dimensions of a new ecological modernisation of agriculture that could "feed the world". Glob. Environ. Chang. 2011, 21, 441-452. [CrossRef]

14. Duru, M.; Therond, O. Livestock system sustainability and resilience in intensive production zones: Which form of ecological modernization? Reg. Environ. Chang. 2015, 15, 1651-1665. [CrossRef]

15. Duru, M.; Therond, O.; Fares, M. Designing agroecological transitions; A review. Agron. Sustain. Dev. 2015, 35, 1237-1257. [CrossRef]

16. van Leeuwen, T. The application of bibliometric analyses in the evaluation of social science research. Who benefits from it, and why it is still feasible. Scientometrics 2006, 66, 133-154. [CrossRef]

17. CiteSpace: Visualizing Patterns and Trends in Scientific Literature. Available online: http://cluster.cis.drexel. edu/ \{\}cchen/citespace/ (accessed on 24 September 2020).

18. Chen, C. CiteSpace II: Detecting and visualizing emerging trends and transient patterns in scientific literature. J. Am. Soc. Inf. Sci. Technol. 2006, 57, 359-377. [CrossRef]

19. Wu, Y.; Wang, H.; Wang, Z.; Zhang, B.; Meyer, B.C. Knowledge mapping analysis of rural landscape using CiteSpace. Sustainability 2020, 12, 66. [CrossRef]

20. Fang, Y.; Yin, J.; Wu, B. Climate change and tourism: A scientometric analysis using CiteSpace. J. Sustain. Tour. 2018, 26, 108-126. [CrossRef]

21. Yao, L.; Hui, L.; Yang, Z.; Chen, X.; Xiao, A. Freshwater microplastics pollution: Detecting and visualizing emerging trends based on Citespace II. Chemosphere 2020, 245, 125627. [CrossRef]

22. Brandes, U.; Delling, D.; Gaertler, M.; Görke, R.; Hoefer, M.; Nikoloski, Z.; Wagner, D. On modularity clustering. IEEE Trans. Knowl. Data Eng. 2008, 20, 172-188. [CrossRef]

23. Kleinberg, J. Bursty and Hierarchical Structure in Streams. Data Min. Knowl. Discov. 2003, 7, $373-397$. [CrossRef]

24. Tscharntke, T.; Klein, A.M.; Kruess, A.; Steffan-Dewenter, I.; Thies, C. Landscape perspectives on agricultural intensification and biodiversity-Ecosystem service management. Ecol. Lett. 2005, 8, 857-874. [CrossRef]

25. Altieri, M.A.; Nicholls, C.I. Agroecology: A brief account of its origins and currents of thought in Latin America. Agroecol. Sustain. Food Syst. 2017, 41, 231-237. [CrossRef]

26. Morel, K.; Revoyron, E.; San Cristobal, M.; Baret, P.V. Innovating within or outside dominant food systems? Different challenges for contrasting crop diversification strategies in Europe. PLoS ONE 2020, 15, e0229910. [CrossRef]

27. Altieri, M.A.; Toledo, V.M. The agroecological revolution in Latin America: Rescuing nature, ensuring food sovereignty and empowering peasants. J. Peasant Stud. 2011, 38, 587-612. [CrossRef]

28. Rosset, P.M.; Sosa, B.M.; Jaime, A.M.R.; Lozano, D.R.Á. The Campesino-to-Campesino agroecology movement of ANAP in Cuba: Social process methodology in the construction of sustainable peasant agriculture and food sovereignty. J. Peasant Stud. 2011, 38, 161-191. [CrossRef] 
29. Tessier, L.; Bijttebier, J.; Marchand, F.; Baret, P.V. Pathways of action followed by Flemish beef farmers-an integrative view on agroecology as a practice. Agroecol. Sustain. Food Syst. 2020. [CrossRef]

30. Gliessman, S. Agroecology: Growing the roots of resistance. Agroecol. Sustain. Food Syst. 2013, 37, $19-31$. [CrossRef]

31. Mier y Terán Giménez Cacho, M.; Giraldo, O.F.; Aldasoro, M.; Morales, H.; Ferguson, B.G.; Rosset, P.; Khadse, A.; Campos, C. Bringing agroecology to scale: Key drivers and emblematic cases. Agroecol. Sustain. Food Syst. 2018, 42, 637-665. [CrossRef]

32. Schiller, K.J.F.; Klerkx, L.; Poortvliet, P.M.; Godek, W. Exploring barriers to the agroecological transition in Nicaragua: A Technological Innovation Systems Approach. Agroecol. Sustain. Food Syst. 2020, 44, 88-132. [CrossRef]

33. López-García, D.; García-García, V.; Sampedro-Ortega, Y.; Pomar-León, A.; Tendero-Acin, G.; Sastre-Morató, A.; Correro-Humanes, A. Exploring the contradictions of scaling: Action plans for agroecological transition in metropolitan environments. Agroecol. Sustain. Food Syst. 2020, 44, 467-489. [CrossRef]

34. Levidow, L.; Sansolo, D.; Schiavinatto, M. Agroecological practices as territorial development: An analytical schema from Brazilian case studies. J. Peasant Stud. 2019. [CrossRef]

35. Cuéllar-Padilla, M.; Calle-Collado, Á. Can we find solutions with people? Participatory action research with small organic producers in Andalusia. J. Rural Stud. 2011, 27, 372-383. [CrossRef]

36. Kennedy, C.M.; Lonsdorf, E.; Neel, M.C.; Williams, N.M.; Ricketts, T.H.; Winfree, R.; Bommarco, R.; Brittain, C.; Burley, A.L.; Cariveau, D.; et al. A global quantitative synthesis of local and landscape effects on wild bee pollinators in agroecosystems. Ecol. Lett. 2013, 16, 584-599. [CrossRef]

37. Gonthier, D.J.; Ennis, K.K.; Farinas, S.; Hsieh, H.-Y.; Iverson, A.L.; Batáry, P.; Rudolphi, J.; Tscharntke, T.; Cardinale, B.J.; Perfecto, I. Biodiversity conservation in agriculture requires a multi-scale approach. Proc. $R$. Soc. B Biol. Sci. 2014, 281, 20141358. [CrossRef]

38. Wood, S.A.; Karp, D.S.; DeClerck, F.; Kremen, C.; Naeem, S.; Palm, C.A. Functional traits in agriculture: Agrobiodiversity and ecosystem services. Trends Ecol. Evol. 2015, 30, 531-539. [CrossRef]

39. Lichtenberg, E.M.; Kennedy, C.M.; Kremen, C.; Batáry, P.; Berendse, F.; Bommarco, R.; Bosque-Pérez, N.A.; Carvalheiro, L.G.; Snyder, W.E.; Williams, N.M.; et al. A global synthesis of the effects of diversified farming systems on arthropod diversity within fields and across agricultural landscapes. Glob. Chang. Biol. 2017, 23, 4946-4957. [CrossRef]

40. Saunders, M.E.; Peisley, R.K.; Rader, R.; Luck, G.W. Pollinators, pests, and predators: Recognizing ecological trade-offs in agroecosystems. Ambio 2016, 45, 4-14. [CrossRef]

41. Kremen, C.; Iles, A.; Bacon, C. Diversified Farming Systems: An Agroecological, Systems-based Alternative to Modern Industrial Agriculture. Ecol. Soc. 2012, 17, 44. [CrossRef]

42. Kremen, C.; Miles, A. Ecosystem Services in Biologically Diversified versus Conventional Farming Systems: Benefits, Externalities, and Trade-Offs. Ecol. Soc. 2012, 17, 40. [CrossRef]

43. Bellon, M.R.; Kotu, B.H.; Azzarri, C.; Caracciolo, F. To diversify or not to diversify, that is the question. Pursuing agricultural development for smallholder farmers in marginal areas of Ghana. World Dev. 2020, 125, 104682. [CrossRef] [PubMed]

44. Martin, G.; Magne, M.A. Agricultural diversity to increase adaptive capacity and reduce vulnerability of livestock systems against weather variability-A farm-scale simulation study. Agric. Ecosyst. Environ. 2015, 199, 301-311. [CrossRef]

45. Iles, A.; Marsh, R. Nurturing Diversified Farming Systems in Industrialized Countries: How Public Policy Can Contribute. Ecol. Soc. 2012, 17, 42. [CrossRef]

46. Bacon, C.M.; Getz, C.; Kraus, S.; Montenegro, M.; Holland, K. The Social Dimensions of Sustainability and Change in Diversified Farming Systems. Ecol. Soc. 2012, 17, 41. [CrossRef]

47. Díaz, S.; Quétier, F.; Cáceres, D.M.; Trainor, S.F.; Pérez-Harguindeguy, N.; Bret-Harte, M.S.; Finegan, B.; Peña-Claros, M.; Poorter, L. Linking functional diversity and social actor strategies in a framework for interdisciplinary analysis of nature's benefits to society. Proc. Natl. Acad. Sci. USA 2011, 108, 895-902. [CrossRef]

48. Van Zonneveld, M.; Turmel, M.S.; Hellin, J. Decision-Making to Diversify Farm Systems for Climate Change Adaptation. Front. Sustain. Food Syst. 2020, 4, 32. [CrossRef] 
49. Narloch, U.; Drucker, A.G.; Pascual, U. Payments for agrobiodiversity conservation services for sustained on-farm utilization of plant and animal genetic resources. Ecol. Econ. 2011, 70, 1837-1845. [CrossRef]

50. Isakson, S.R. No hay ganancia en la milpa: The agrarian question, food sovereignty, and the on-farm conservation of agrobiodiversity in the Guatemalan highlands. J. Peasant Stud. 2009, 36, 725-759. [CrossRef]

51. Keleman, A.; Hellin, J.; Bellon, M.R. Maize diversity, rural development policy, and farmers' practices: Lessons from Chiapas, Mexico. Geogr. J. 2009, 175, 52-70. [CrossRef]

52. Zimmerer, K.S. The compatibility of agricultural intensification in a global hotspot of smallholder agrobiodiversity (Bolivia). Proc. Natl. Acad. Sci. USA 2013, 110, 2769-2774. [CrossRef] [PubMed]

53. Kerr, R.B. Lost and Found Crops: Agrobiodiversity, Indigenous Knowledge, and a Feminist Political Ecology of Sorghum and Finger Millet in Northern Malawi. Ann. Assoc. Am. Geogr. 2014, 104, 577-593. [CrossRef]

54. Krishna, V.V.; Drucker, A.G.; Pascual, U.; Raghu, P.T.; King, E.D.I.O. Estimating compensation payments for on-farm conservation of agricultural biodiversity in developing countries. Ecol. Econ. 2013, 87, 110-123. [CrossRef]

55. Narloch, U.; Pascual, U.; Drucker, A.G. Cost-effectiveness targeting under multiple conservation goals and equity considerations in the Andes. Environ. Conserv. 2011, 38, 417-425. [CrossRef]

56. Zimmerer, K.S. Conserving agrobiodiversity amid global change, migration, and nontraditional livelihood networks: The dynamic uses of cultural landscape knowledge. Ecol. Soc. 2014, 19, 1. [CrossRef]

57. Stromberg, P.M.; Pascual, U.; Bellon, M.R. Seed systems and farmers' seed choices: The case of maize in the Peruvian Amazon. Hum. Ecol. 2010, 38, 539-553. [CrossRef]

58. Krishna, V. Farm Production Diversity and Dietary Diversity in Developing Countries. Open Access J. 2015, 112, 10657-10662. [CrossRef]

59. Ng'Endo, M.; Keding, G.B.; Bhagwat, S.; Kehlenbeck, K. Variability of on-farm food plant diversity and its contribution to food security: A case study of smallholder farming households in western Kenya. Agroecol. Sustain. Food Syst. 2015, 39, 1071-1103. [CrossRef]

60. Segnon, A.C.; Achigan-Dako, E.G. Comparative analysis of diversity and utilization of edible plants in arid and semi-arid areas in Benin. J. Ethnobiol. Ethnomed. 2014, 10, 80. [CrossRef]

61. Powell, B.; Thilsted, S.H.; Ickowitz, A.; Termote, C.; Sunderland, T.; Herforth, A. Improving diets with wild and cultivated biodiversity from across the landscape. Food Secur. 2015, 7, 535-554. [CrossRef]

62. Nordhagen, S.; Pascual, U.; Drucker, A.G. Feeding the Household, Growing the Business, or Just Showing Off? Farmers' Motivations for Crop Diversity Choices in Papua New Guinea. Ecol. Econ. 2017, 137, 99-109. [CrossRef]

63. Altieri, M.A. Agroecology: The science of natural resource management for poor farmers in marginal environments. Agric. Ecosyst. Environ. 2002, 93, 1-24. [CrossRef]

64. Nicholls, C.I.; Altieri, M.A. Pathways for the amplification of agroecology. Agroecol. Sustain. Food Syst. 2018, 42, 1170-1193. [CrossRef]

65. Zhang, W.; Ricketts, T.H.; Kremen, C.; Carney, K.; Swinton, S.M. Ecosystem services and dis-services to agriculture. Ecol. Econ. 2007, 64, 253-260. [CrossRef]

66. Migliorini, P.; Gkisakis, V.; Gonzalvez, V.; Raigón, M.D.; Bàrberi, P. Agroecology in mediterranean Europe: Genesis, state and perspectives. Sustainability 2018, 10, 2724. [CrossRef]

67. Picchi, M.S.; Bocci, G.; Petacchi, R.; Entling, M.H. Effects of local and landscape factors on spiders and olive fruit flies. Agric. Ecosyst. Environ. 2016, 222, 138-147. [CrossRef]

Publisher's Note: MDPI stays neutral with regard to jurisdictional claims in published maps and institutional affiliations.

(C) 2020 by the authors. Licensee MDPI, Basel, Switzerland. This article is an open access article distributed under the terms and conditions of the Creative Commons Attribution (CC BY) license (http://creativecommons.org/licenses/by/4.0/). 